\title{
Adrenal Response to ACTH in Patients with Prader- Willi Syndrome, Simple Obesity, and Constitutional Dwarfism
}

\author{
B. T. RUDD, G. W. CHANCE, and C. G. THEODORIDIS \\ From Institute of Child Health, University of Birmingham
}

In 1956 Prader, Labhart, and Willi first described a group of patients who presented with 'floppiness' at birth and later became obese, dwarfed, and mentally retarded, and some had impaired glucose tolerance tests. Further articles followed (Prader and Willi, 1961; Laurance, 1961, 1967; Forssman and Hagberg, 1964; Evans, 1964; Hooft, Delire, and Casneuf, 1966).

Laurance gave a detailed description of the syndrome. The features which he considered characteristic were obesity, mental retardation, hypogonadism, hypotonia, shortness of stature, prominent forehead, almond-shaped eyes, retroussé nose, small fish-like mouth, short hands and feet. All of them were floppy at birth and some of them showed a diabetic type of glucose tolerance test. Laurance concluded that the adrenal function was normal in these patients, but Forssman and Hagberg reported a reduced response to ACTH. In the present paper we report a comparison of the plasma cortisol response to ACTH in 22 subjects, 6 of whom were children showing the features of Prader-Willi syndrome as described above. Of the remainder, 6 were children with constitutional short stature, 4 were children with simple obesity, and 6 were healthy adolescents with no known metabolic disease. Evidence is also presented from the results of long-term ACTH ( 3 days) in 2 cases of Prader-Willi syndrome that the urinary 17-OHCS output parallels their plasma cortisol response.

\section{Materials and Methods}

Plasma cortisol was estimated by the fluorimetric procedure of Rudd, Sampson, and Brooke (1963). The output of 17-OHCS in the urine was measured as Porter-Silber chromogens, employing a modification of the colorimetric procedure of Silber and Porter (1954). Urinary steroid data are expressed in terms of body

Received September 11, 1968. weight, in view of the close correlation of steroid excretion rates with this body parameter under basal conditions (Tanner et al., 1959), and under conditions of adrenocortical stimulation with ACTH (Prezio et al., 1964).

ACTH test. Short-term and long-term tests were carried out.

(1) Short-term. Plasma cortisol levels were measured before and after a single injection of ACTH. The test was conducted in the following manner.

A venous sample of heparinized plasma was obtained at 10 a.m. (basal); 40 I.U. ACTH (Organon Zinc) were then given intramuscularly and further blood samples were obtained at 2,4 , and 6 hours after the injection of ACTH (Jenkins, Pilkington, and Rosenoer, 1960).

(2) Long-term (3-day ACTH test). 17-OHCS were measured before and after three consecutive days of adrenocortical stimulation with ACTH. The procedure adopted was similar to that described by Clayton, Edwards, and Renwick (1963). A baseline 24-hour urine was collected on the first day. 20 I.U. ACTH (Crookes $\mathrm{Gel}$ ) were then given intramuscularly twice daily (6 a.m. and 6 p.m.) for 3 consecutive days, and 24-hour urine samples were collected on each day. The creatinine content of each urine was measured as an index of accurate daily collection.

\section{Results}

The clinical findings in the 6 children with Prader-Willi syndrome (Cases 17 to 22) are shown in Table I. The plasma cortisol responses obtained in the four groups are shown in Table II. Table III shows the age and body parameters of the patients with constitutional shortness of stature (Cases 7-12), and simple obesity (Cases 13-16). Our normal controls were 6 healthy young adults (Cases 1-6), 3 male and 3 female of normal height and weight whose ages ranged from $16 \frac{1}{2}$ to 19 years, mean 18 years. As an index of a normal response to ACTH, the mean responses 
TABLE I

Details of 6 Cases with Prader-Willi Syndrome

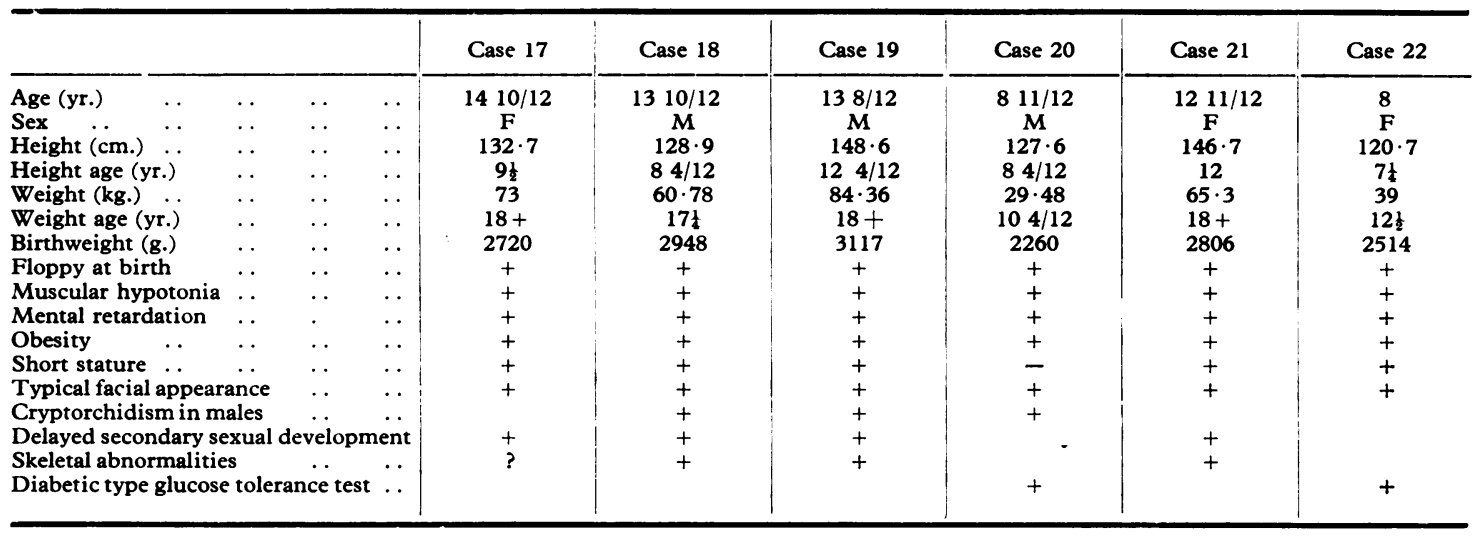

TABLE II

Plasma Cortisol Levels after ACTH

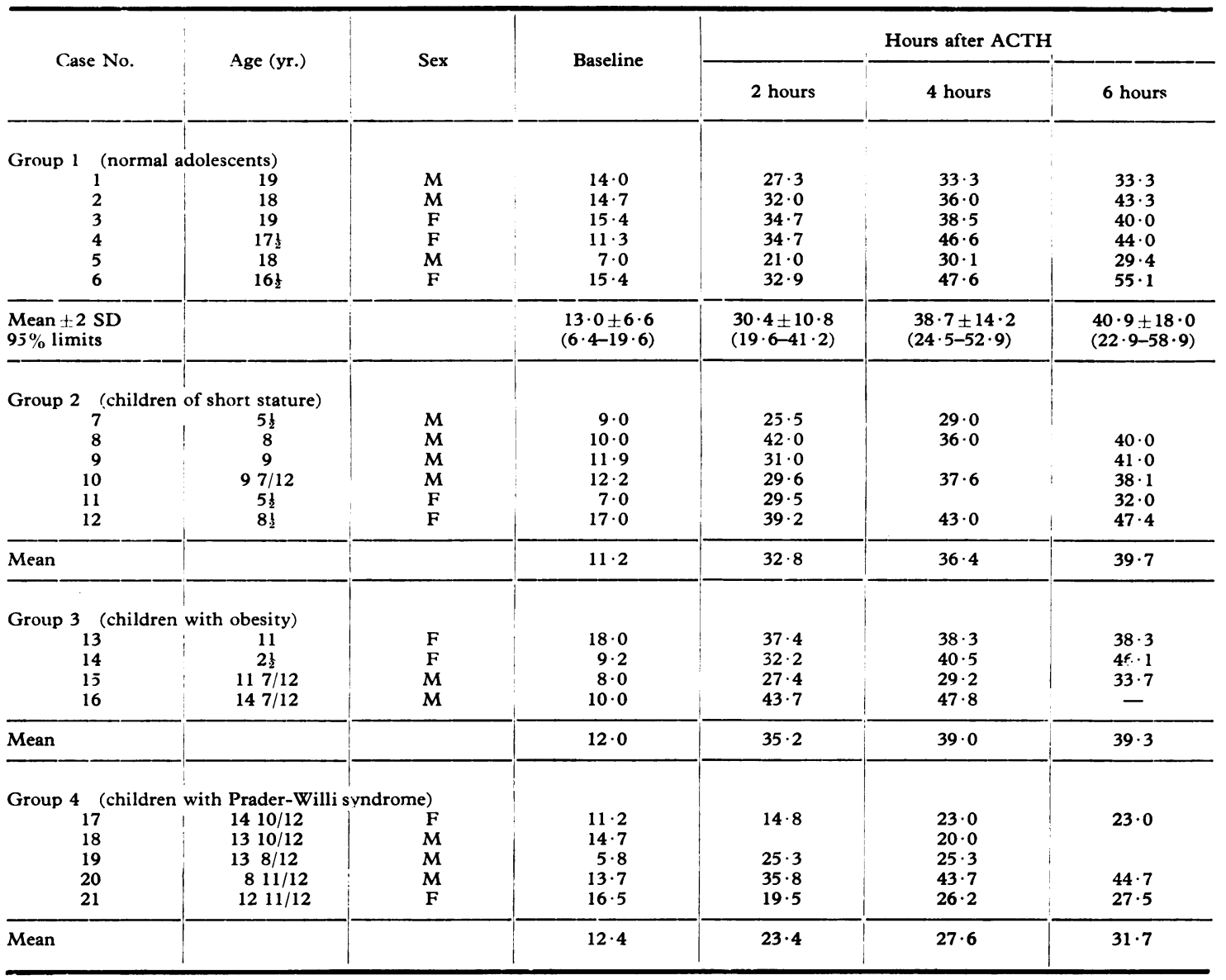


TABLE III

Cases with Short Stature (7-12), and with Obesity (13-16)

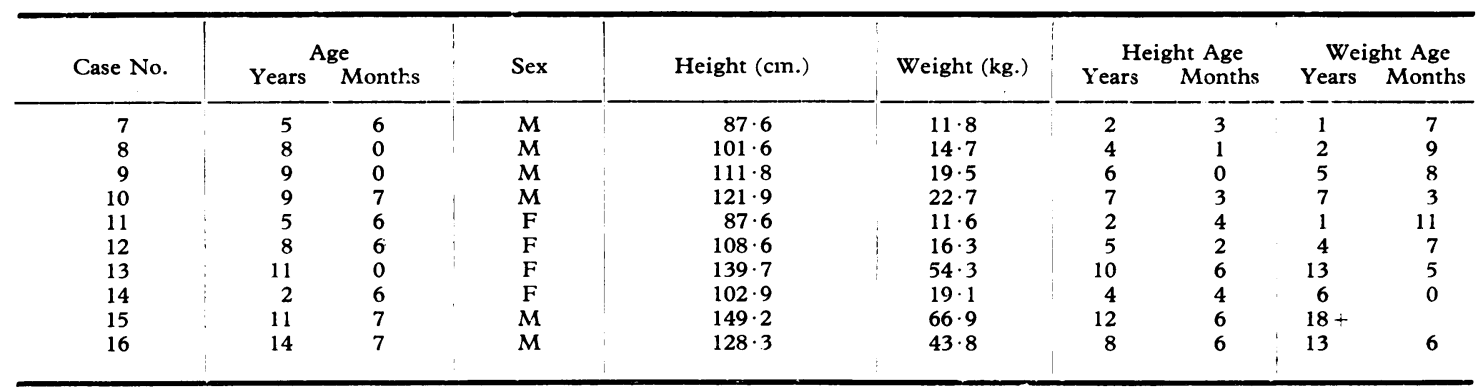

( \pm 2 SD) found for the young adults 4 hours after ACTH have been used, and they were for this normal graph $38 \cdot 7 \pm 14 \cdot 2 \mu \mathrm{g}$. cortisol $/ 100 \mathrm{ml}$. plasma.

Individual values obtained at 4 hours in the children with constitutional dwarfism were within the normal limits. Similar responses were obtained for the patients with simple obesity. The obese children compared with the children with constitutional short stature showed slightly higher, but statistically insignificant mean values. When individual values for the children with Prader-Willi syndrome were compared to the normal controls at 4 hours after ACTH, 2 of the 5 patients (Cases 17 and 18) showed a response outside the $95 \%$ confidence limits, 2 had responses at the lower limits of normal (Cases 19 and 21), and 1 had a normal response (Case 20).

Two patients with Prader-Willi syndrome were also studied after ACTH stimulation for 3 days

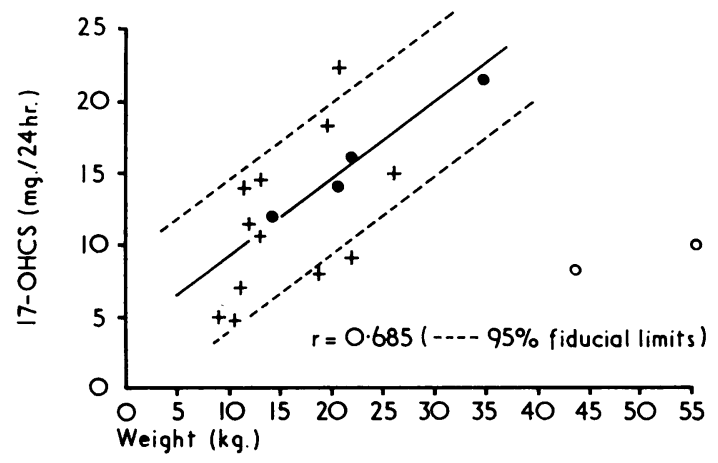

FIG. 1.-Mean (3-day) responses to ACTH. $+==$ short children; $\mathrm{O}=$ normal stature (early puberty); $\mathrm{O}=$ Prader-Willi syndrome.
(Cases 17 and 22). In Fig. 1 values of 17-OHCS obtained for these 2 children are shown with the mean excretion rate obtained in 12 children with short stature and 4 children of normal stature in early puberty.

The 2 patients with Prader-Willi syndrome failed to produce an adequate 17-OHCS excretion after the prolonged stimulation with ACTH. Case 17 also had a poor response to ACTH in the shortterm test.

\section{Discussion}

Investigations of the function of the pituitary and adrenal cortex have given normal results in most cases (Laurance, 1967), but in Forssman and Hagberg's patient there was a poor response to ACTH. The results reported here show that in some patients with Prader-Willi syndrome a

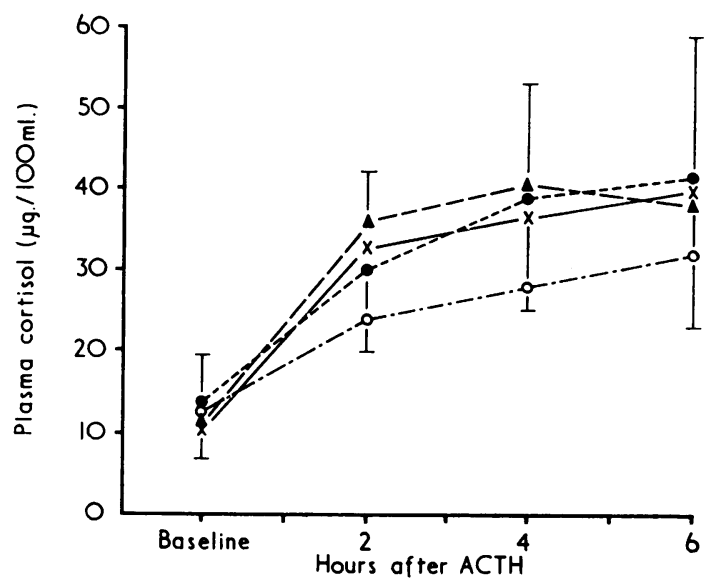

Fig. 2.-Plasma cortisol levels in the 4 groups after ACTH stimulation. $\mathbf{O}=$ normals $( \pm 2 S D) ; \Delta=$ obesity; $\times=$ short children; $\mathrm{O}=$ Prader-Willi syndrome. 
partial failure of adrenal response is present. 3 out of the 6 children with Prader-Willi syndrome had a poor response to ACTH, and when the results are compared with those obtained in children with short stature or simple obesity, these responses are still abnormal. It appears then that neither shortness of stature nor obesity are the factors responsible for the inadequate responses.

The children with Prader-Willi syndrome were, on average, heavier than the children in the other two groups, and the possibility therefore exists that since a fixed dose (40 I.U.) of ACTH was used for adrenal stimulation, when plasma cortisols were measured, a submaximal dose might have contributed to the reduced responses. We feel that this explanation is unlikely, however. The dose of ACTH employed was that suggested by Jenkins (1961), who showed that 40 I.U. produced an adequate plasma cortisol response in normal adults at 4 hours. In addition, the 2 children with Prader-Willi syndrome who were re-investigated using the 3-day stimulation test did not show any evidence of a normal increase in 17-OHCS output, despite the fact that a total dose of 120 units of ACTH was used.

\section{Summary}

Adrenal function in 6 children with Prader-Willi syndrome was evaluated. 2 of 5 had a poor cortisol response to short-term ACTH stimulation. Further studies using a long-term ACTH test with measurement of 17-OHCS urinary excretion in 2 of the children confirmed that adrenal function was deficient.

Neither adiposity nor shortness of stature appeared to be directly concerned in this defective adrenal response to ACTH stimulation, because similar tests applied to 6 children with constitutional short stature, 4 children with simple obesity, and 6 healthy adolescents gave normal results.
We are grateful to Professor D. V. Hubble, Dr. Margaret I. Griffiths, and Professor B. Laurance for allowing us to perform these investigations on their patients.

\section{REFERENCES}

Clayton, B. E., Edwards, R. W. H., and Renwick, A. G. C. (1963). Adrenal function in children. Arch. Dis. Childh., 38, 49.

Evans, P. R. (1964). Hypogenital dystrophy with diabetic tendency. Guy's Hosp. Rep., 113, 207.

Forssman, H., and Hagberg, B. (1964). Prader-Willi syndrome in boy of ten with prediabetes. Acta paediat. (Uppsala), 53, 70.

Hooft, C., Delire, C., and Casneuf, J. (1966). Le syndrome de Prader-Labhardt-Willi-Fanconi. Acta paediat. belg., 20. 27.

Jenkins, J. S. (1961). Adrenocortical hormones in the blood. In The Adrenal Cortex, (Symposium Organised by The Association of Clinical Pathologists), p. 33. Ed. by G. K. McGowan and M. Sandler. Pitman, London.

-, Pilkington, T. R. E., and Rosenoer, V. M. (1960). Thyrotoxicosis and Addison's disease in same patient. Brit. med. $\mathcal{F}$., $1,1025$.

Laurance, B. M. (1961). Hypotonia, obesity, hypogonadism and mental retardation in childhood. Arch. Dis. Childh., 36, 690.

- (1967). Hypotonia, mental retardation, obesity, and cryptorchidism associated with dwarfism and diabetes in children. ibid., 42, 126.

Prader, A., Labhart, A., and Willi, H. (1956). Ein Syndrom von Adipositas, Kleinwuchs, Kryptorchismus und Oligophrenie nach myatonieartigem Zustand im Neugeborenenalter. Schweiz. med. Wschr., 86, 1260.

- - and Willi,H. (1961). Das Syndrom von Ibezillität, Adipositas, Muskelhypotonie, Hypogenitalismus, Hypogonadismus und Diabetes Mellitus mit 'Myatonie' Anamnese. Verh. 2 int. Kongr. Psych. Entw. Stez. Kindesalt., Wien, 1961, pt. I. p. 353.

Prezio, J. A., Carreon, G., Clerkin, E., Meloni, C. R., Kyle, L. H., and Canary, J. J. (1964). Influence of body composition on adrenal function in obesity. $\mathcal{f}$. clin. Endocr., $24,481$.

Rudd, B. T., Sampson, P., and Brooke, B. N. (1963). A new fluorimetric method of plasma cortisol assay with a study of pituitary-adrenal function using metyrapone. $\mathcal{f}$. Endocr., 27, 317.

Silber, R. H., and Porter, C. C. (1954). The determination of 17, 21-dihydroxy-20-ketosteroids in urine and plasma. $f$. biol. Chem., 210, 923.

Tanner, J. M., Healy, M. J. R., Whitehouse, R. H., and Edgson, A. C. (1959). The relation of body build to the excretion of 17-ketosteroids and 17-ketogenic steroids in healthy young men. f. Endocr., 19, 87.

Correspondence to Dr. C. G. Theodoridis, Institute of Child Health, University of Birmingham, The Nuffield Building, Francis Road, Birmingham 16. 